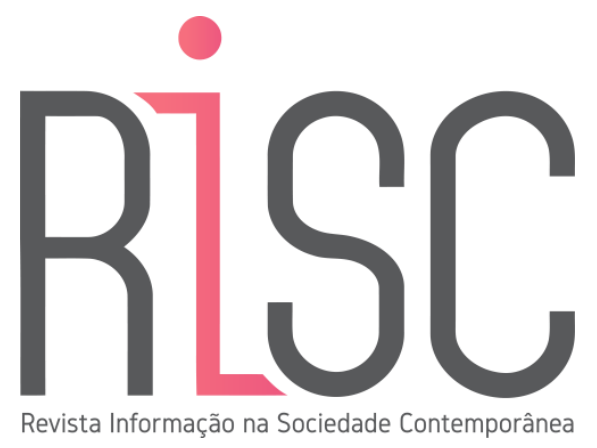

\title{
QUE INFORMAÇÕES SÃO UTILIZADAS DURANTE O TRATAMENTO DE FERIDAS?
}

\section{Paulo Vanzolini Moura da Silva}

Bacharelando em Tecnologia da Informação

Universidade Federal do Rio Grande do Norte, Natal, RN, Brasil

https://orcid.org/0000-0001-6595-564X E-mail:p.vanzolini@hotmail.com

\section{Bruno Santana da Silva}

Doutor em Informática pela PUC-Rio

Universidade Federal do Rio Grande do Norte, Natal, RN, Brasil

https://orcid.org/0000-0002-7689-8000 E-mail: bruno@imd.ufrn.br

Submetido em: $17-12-2020$

Reapresentado em: 23-02-2021

Aceito em: 30-03-2021

\section{RESUMO}

Durante o tratamento de feridas, profissionais de enfermagem precisam consultar várias informações para decidirem o que fazer e precisam registrar as informações produzidas. Este trabalho relata uma investigação sobre as necessidades informacionais de profissionais de enfermagem durante o tratamento de feridas. Foi aplicado um questionário com 14 perguntas para 50 participantes de um curso de Terapia Larval, um tipo de tratamento de feridas. O questionário abordava o perfil dos participantes e suas necessidades informacionais. Após a análise descritiva individual dos dados coletados em cada pergunta, analisou-se possíveis relações entre algumas respostas para verificar a influência do perfil do participante sobre sua necessidade informacional. Identificou-se informações importantes sobre o paciente, suas feridas, fontes de informação utilizadas, modos de registro de informações produzidas durante os atendimentos, e sobre os tipos de apoio informacional que um software poderia oferecer para apoiar o tratamento de feridas. Uma melhor compreensão das necessidades informacionais durante o tratamento serve de insumo para 
o oferecimento de um melhor suporte informacional aos profissionais e pacientes envolvidos.

Palavras-chave: Necessidades de informação. Fontes de Informação. Informação em saúde. Sistemas de informação.

\section{WHAT INFORMATION IS USED DURING WOUND TREATMENT?}

\section{ABSTRACT}

During treatment of wounds, nursing professionals need to consult several information to decide what to do and need to record the information produced. This paper reports an investigation into the information needs of nursing professionals during the treatment of wounds. A 14-questions questionnaire was applied to 50 participants in a Larval Therapy course, a type of wound treatment. The questionnaire addressed the participants' profile and their information needs. After the individual descriptive analysis of the collected data in each question, possible relationships among some answers were analyzed to verify the influence of the participants' profile on their information need. Important information was identified about patient, his wounds, sources of information used, ways of recording information produced during the wound care, and about the kinds of informational support software could offer to wound care. A better understanding of information needs during wound treatment can help to improve informational support to health professionals.

Keywords: Information needs. Information sources. Health information. Information storage and retrieval systems.

\section{INTRODUÇÃO}

Cuidados com a saúde exigem considerações sobre um grande volume e variedade de informações. Feridas na pele são um problema de saúde comum que pode comprometer a qualidade de vida das pessoas, especialmente se forem feridas crônicas. Muitos profissionais de saúde participam do tratamento de feridas, mas os profissionais de enfermagem tendem a se envolverem mais neste processo.

O trabalho de um enfermeiro durante a prestação de assistência a um paciente é orientado pelo processo de enfermagem (GARCIA; NOBREGA, 2009), que define as seguintes etapas: coleta de dados de enfermagem, diagnóstico de enfermagem, planejamento de enfermagem, implementação e avaliação. Este processo geral pode ser detalhado para o tratamento de feridas como: o enfermeiro inicia o atendimento 
analisando o histórico de saúde do paciente e o histórico da ferida; depois, ele faz um diagnóstico da situação atual de saúde do paciente e da ferida para então realizar o tratamento da ferida e da cicatriz; por fim, o enfermeiro cobre a ferida (coloca um curativo) e registra informações sobre o tratamento realizado para compor o histórico do paciente (KORDESTANI, 2019; SANTOS et al., 2011).

A execução do tratamento de feridas envolve consulta, produção e registro de várias informações entre pacientes e profissionais de saúde. Diferentes tecnologias da informação e comunicação têm sido utilizadas em conjunto para dar suporte a esse processo: papel e caneta, fotos, vídeos e mais recentemente softwares e hardwares de informática. Esses últimos têm recebido maior atenção na área da saúde pelo seu poder de processamento de informações, pela capacidade de trabalhar com grande quantidade de informações e pela convergência.

A literatura apresenta várias iniciativas de desenvolvimento da informática em apoio ao tratamento de feridas. Entretanto, ainda se faz necessário investigar melhor a necessidade informacional dos profissionais de enfermagem durante o tratamento de feridas. Que informações os profissionais de enfermagem necessitam consultar para realizar seu trabalho durante o tratamento de feridas? Como eles costumam obter tais informações? De que maneiras um sistema computacional poderia auxiliá-los a lidar com essas informações? Motivado por questionamentos como esses, este trabalho realizou um survey para analisar quais informações são utilizadas durante o tratamento de feridas (MARTINEZ-SILVEIRA; ODDONE, 2007; FIGUEIREDO, 1994).

\section{METODOLOGIA}

Este trabalho relata uma pesquisa quantitativa descritiva (CRESWELL, 2010) sobre as necessidades informacionais (MARTINEZ-SILVEIRA; ODDONE, 2007; FIGUEIREDO, 1994) dos enfermeiros durante o tratamento de feridas. Para tanto, utilizou-se o método de survey (FINK, 2003) através de um questionário com 14 perguntas. Quase todas as perguntas foram fechadas (ofereciam opções pré-definidas de respostas e uma opção "outros"), exceto a última pergunta de resposta livre. O questionário foi distribuído impresso em papel durante um curso de Terapia Larval, um tipo de tratamento de 
feridas, na Universidade Federal do Rio Grande do Norte em setembro de 2019. Os participantes do curso foram avisados de que preenchimento do questionário era facultativo e voluntário. Todos os 50 participantes do curso devolveram o questionário preenchido de forma anônima.

\section{PERFIL DOS PARTICIPANTES}

A faixa etária dos participantes variou entre 18 e 49 anos, sem concentração significativa de participantes em um faixa etária particular. Foram 16 participantes entre 18 e 24 anos (32\%), 11 entre 25 e 29 anos (22\%), 14 entre 30 e 39 anos (28\%) e 9 participantes entre 40 e 49 anos (18\%). A maioria (84\%) dos participantes são da área de enfermagem distribuídos em 11 técnicos em enfermagem (22\%), 15 estudantes de bacharelado em enfermagem (30\%) e 16 enfermeiros (32\%). Os demais participantes são 3 agentes comunitários (6\%) e 5 pessoas de outras profissões (10\%) com interesse no tratamento de feridas.

Dos 23 participantes com atuação profissional em enfermagem, 6 atendem em domicílio (11\%), 9 trabalham em hospital (17\%) e 11 trabalham em postos de saúde (21\%). Os demais participantes indicaram outras atuações profissionais (17\%) ou não responderam esta questão (34\%). O grande número de respostas em branco desta questão pode estar relacionado com o fato de muitos participantes ainda serem estudantes de graduação.

Um grupo de 27 participantes (54\%) afirmou não ter experiência profissional com tratamento de feridas. Destes, 1 participante não respondeu esta pergunta (2\%), 3 não são profissionais de saúde (6\%) e 23 participantes não tem experiência (46\%). No grupo de 23 participantes (46\%) com experiência profissional no tratamento de feridas, observou-se uma distribuição equilibrada nos seus tempos de experiência. A maioria possuía poucos anos de experiência, com 7 participantes (14\%) entre 6 meses e 2 anos de experiência, seguidos por 6 participantes (12\%) com mais de 2 anos e menos de 5 anos de experiência. Os extremos formam o menor grupo de participantes, com 6 participantes (12\%) com menos de 6 meses de experiência e outros 4 participantes (8\%) com mais de 5 anos de experiência. 
Os participantes apresentaram uma frequência diária média de atendimento a pacientes com feridas bem discrepante. Um total de 18 participantes (36\%) relataram não tratar de pacientes com feridas. Os demais 32 participantes (64\%) relataram realizar este tipo de tratamento com alguma frequência diária. A grande maioria (56\%) costuma tratar poucos pacientes com feridas diariamente, com 8 participantes (18\%) tratando de menos de 1 paciente por dia e 19 participantes (38\%) tratando de 2 até 5 pacientes por dia. Poucos (8\%) relataram uma quantidade mais alta de atendimentos diários, com 3 participantes (6\%) atendendo de 6 até 15 pacientes e apenas 1 participante (2\%) atendendo mais de 15 pacientes diários.

A maioria dos participantes relataram familiaridade com informática. Computador pessoal, celular e tablets já tinham sido usados por, respectivamente, 42 (84\%), 34 (68\%) e 12 (24\%) dos participantes. Estes dispositivos serviram de acesso a uma diversidade de softwares, tais como: redes sociais para 45 participantes (90\%), e-mail para 40 participantes (80\%), softwares de escritório (editores de texto, planilhas eletrônicas, etc.) para 37 participante (74\%), sites de notícias para 31 participantes (62\%) e jogos digitais para 14 participantes (28\%). Esse comportamento não pode ser definido como avesso ou resistente ao uso de informática.

\section{NECESSIDADES INFORMACIONAIS DOS PARTICIPANTES}

Os participantes indicaram uma diversidade de informações relevantes no tratamento de feridas. Alguns escreveram respostas livres recorrentes na opção "outros" de modo significativo, apesar de não terem frequência tão alta comparado às opções de resposta fechadas apresentadas no questionário. Espontaneamente, 2 participantes (4\%) afirmaram ser relevante considerar aspectos sociodemográficos do paciente durante o tratamento de feridas; 3 participantes (6\%) acreditam que aspectos socioeconômicos devem ser considerados; e 4 participantes (8\%) dizem ser importante considerar a nutrição e aspectos psicossociais do paciente nesse cuidado com a saúde.

Nas opções de resposta oferecidas explicitamente no questionário, 12 participantes (24\%) acreditam que medicamentos consumidos e exames laboratoriais dos pacientes são informações importantes para se considerar no tratamento de feridas; 29 
participantes (58\%) consideram relevante informações sobre alergias dos pacientes; 34 participantes $(68 \%)$ apontam como significativas as informações sobre tratamentos anteriores das feridas do paciente; e 40 participantes (80\%) defendem considerar doenças crônicas e o histórico de saúde do paciente durante o tratamento de feridas. Sete participantes (14\%) não indicaram nenhuma informação como relevante ao tratamento de feridas, seja ela sugerida pelo questionário ou definida livremente em "outros". Estes participantes não tinham formação área de enfermagem ou ainda eram alunos iniciantes na área.

A maioria dos participantes considerou todas as características da ferida indicadas no questionário como relevantes durante o tratamento. A profundidade da ferida foi importante por 42 participantes (84\%). A aparência e a textura dos tecidos que compõem a ferida são importantes para 38 participantes (76\%). Os tamanhos do contorno e das partes internas são significativos para 36 e 33 participantes (72\% e 66\%), respetivamente.

Os participantes indicaram como costumam obter informações necessárias ao tratamento de feridas. Para a maioria deles, o próprio paciente é a principal fonte de informações sobre seu histórico de saúde, tratamentos anteriores das feridas que recebeu, medicamentos consumidos, suas alergias e doenças crônicas. Apenas os resultados de exames laboratoriais são obtidos principalmente no prontuário do paciente em papel. Ainda que o prontuário do paciente em papel não seja a principal fonte para a maioria das informações consideradas, ele é uma fonte significativa para muitos participantes. Uma quantidade muito pequena (de $2 \%$ até $6 \%$ ) de participantes indicou um software como fonte dessas informações. Nenhum participante indicou software como fonte de informações sobre medicamentos consumidos pelo paciente.

Além de indicar as fontes de informação que costumam utilizar durante o tratamento de feridas, os participantes também indicaram a frequência em que conseguem obter tais informações. A maioria dos participantes sempre consegue obter informações sobre o histórico de saúde, medicamentos consumidos e doenças crônicas do paciente quando julga necessário analisá-las. A maioria dos participantes algumas vez também consegue obter informações sobre os tratamentos anteriores de feridas e exames laboratoriais dos pacientes, mas nem sempre elas estão disponíveis quando 
precisam analisá-las. Poucos participantes afirmam não conseguir obter as informações de que precisam durante o tratamento de feridas.

A grande maioria dos participantes (35 pessoas, 70\%) registra informações sobre o tratamento de feridas em papel. Um número expressivo de 29 participantes (58\%) afirma registrar também fotos das feridas, provavelmente por ser um registro mais fidedigno das suas características visuais. Outras formas de registro de informações sobre o tratamento de feridas foram citadas, mas em quantidade bem menor de vezes. Onze participantes (22\%) realizam anotações em computador. Cinco participantes (10\%) realizam anotações em celular. Um participante (2\%) grava áudio sobre o tratamento de feridas.

Na única pergunta aberta do questionário, os participantes relataram livremente como um software poderia auxiliar seu trabalho durante o tratamento de feridas. Foram identificadas 7 tipos de apoio informacional que um software poderia oferecer: facilitar o diálogo entre profissionais, similar ao que ocorre em um chat ou rede social (2 participantes, $4 \%)$; aumentar a eficiência no atendimento, provavelmente através de um acesso a informações mais rápido (4 participantes, 8\%); facilitar o trabalho dos profissionais de enfermagem, possivelmente delegando ao software algumas (partes das) tarefas (de acesso e processamento de informação) que os profissionais precisam fazer durante o tratamento de feridas (5 participantes, 10\%); apoiar o diagnóstico das feridas (6 participantes, 12\%); melhorar a precisão e eficácia do tratamento de feridas (6 participantes, $12 \%)$; receber orientações sobre como realizar o tratamento de feridas (10 participantes, 20\%); e apoio para visualizar e analisar o histórico do tratamento de feridas (15 participantes, 30\%).

\section{DIFERENÇAS NAS NECESSIDADES INFORMACIONAIS POR PERFIS DE PARTICIPANTES}

Observou-se diferenças nas necessidades informacionais indicadas pelos participantes quando eles foram estratificados por perfis. A Tabela 1 apresenta a porcentagem de participantes que trabalham em um contexto específico e consideram relevante analisar determinadas informações durante o tratamento de feridas, em relação a todos que trabalham naquele contexto. 
Tabela 1 - Porcentagem de participantes que consideram importante consultar determinadas informações em relação a todos os participantes que trabalham naquele contexto.

\begin{tabular}{|c|c|c|c|c|c|c|}
\hline & $\begin{array}{l}\text { histórico de } \\
\text { saúde }\end{array}$ & $\begin{array}{l}\text { doenças } \\
\text { crônicas }\end{array}$ & $\begin{array}{l}\text { tratamentos } \\
\text { anteriores }\end{array}$ & alergias & exames & $\begin{array}{c}\text { medicamentos } \\
\text { consumidos }\end{array}$ \\
\hline $\begin{array}{l}\text { sem resposta ou } \\
\text { experiência }\end{array}$ & $89 \%$ & $83 \%$ & $78 \%$ & $67 \%$ & $61 \%$ & $67 \%$ \\
\hline outros & $44 \%$ & $44 \%$ & $44 \%$ & $33 \%$ & $44 \%$ & $44 \%$ \\
\hline posto de saúde & $82 \%$ & $91 \%$ & $64 \%$ & $45 \%$ & $36 \%$ & $45 \%$ \\
\hline hospital & $100 \%$ & $89 \%$ & $78 \%$ & $78 \%$ & $78 \%$ & $67 \%$ \\
\hline $\begin{array}{c}\text { atendimento em } \\
\text { domicílio }\end{array}$ & $83 \%$ & $83 \%$ & $67 \%$ & $67 \%$ & $33 \%$ & $67 \%$ \\
\hline
\end{tabular}

Histórico de saúde do paciente foi o foco principal de quem trabalha em hospital com $100 \%$ dos participantes, seguido por $83 \%$ de quem atende em domicilio e por $82 \%$ de quem trabalha em posto de saúde. Doenças crônicas foi o foco principal de quem trabalha em posto de saúde com $91 \%$ dos participantes, seguido por $89 \%$ de quem trabalha em hospital e por $83 \%$ de quem atende em domicílio. Para o restante das informações consideradas relevantes, a porcentagem de quem trabalha em hospital foi entre $14 \%$ e $45 \%$ maior do que quem trabalha em outros locais. Já a porcentagem daqueles que atendem em domicílio foi um de $3 \%$ até $22 \%$ maior do que quem trabalha em posto de saúde, exceto em exames laboratoriais em que foi $3 \%$ menor.

A porcentagem dos participantes que consideram características específicas das feridas também variou significativamente dentro de um local de trabalho e entre eles (Tabela 2). Proporcionalmente, a profundidade da ferida foi destaque principal em todos os perfis, para: $100 \%$ dos que realizam atendimento em domicílio, $100 \%$ dos que trabalham em hospital, $94 \%$ dos que não indicaram onde trabalham ou não possuem experiência, $84 \%$ dos que trabalham em posto de saúde e $67 \%$ dos que não trabalham com enfermagem. 
Tabela 2 - Porcentagem dos que trabalham em um contexto e consideram importante analisar determinadas informações sobre as feridas, em relação a todos que trabalham naquele contexto.

\begin{tabular}{ccccc} 
& $\begin{array}{c}\text { tamanho do } \\
\text { contorno }\end{array}$ & $\begin{array}{c}\text { tamanho das } \\
\text { partes internas }\end{array}$ & $\begin{array}{c}\text { aparência e } \\
\text { textura }\end{array}$ & profundidade \\
$\begin{array}{c}\text { sem resposta ou } \\
\text { experiência }\end{array}$ & $78 \%$ & $89 \%$ & $83 \%$ & $94 \%$ \\
\hline $\begin{array}{c}\text { outros } \\
\text { posto de saúde }\end{array}$ & $56 \%$ & $44 \%$ & $67 \%$ & $67 \%$ \\
\hline $\begin{array}{c}\text { hospital } \\
\text { atendimento em } \\
\text { domicílio }\end{array}$ & $73 \%$ & $64 \%$ & $55 \%$ & $82 \%$ \\
\hline
\end{tabular}

Fonte: Participantes da pesquisa.

Já o tamanho do contorno da ferida foi uma das principais características a serem analisadas para $100 \%$ dos que realizam o atendimento em domicílio. No geral, a porcentagem total das pessoas que realizam atendimento em domicílio foi um pouco maior do que aquelas que trabalham em hospital, que por sua vez foi um pouco maior do que aquelas que trabalham em posto de saúde. Internamente, entretanto, os grupos apresentam diferenças significativas. Por exemplo, se por um lado tamanho do contorno e profundidade das feridas foi citado por $100 \%$ dos que atendem em domicílio, apenas $50 \%$ deles apontaram o tamanho das partes internas como relevante. De modo análogo, $100 \%$ dos que trabalham no hospital consideram importante analisar a profundidade, mas apenas $56 \%$ deles indicaram o tamanho do contorno e das partes internas como relevante. Para atender aos diferentes perfis de profissionais todas estas informações deveriam estar disponíveis. Em cada situação, os profissionais irão se concentrar no que for relevante naquele caso específico.

O próprio paciente é a principal fonte das informações relevantes ao tratamento de feridas para aqueles que trabalham no posto de saúde, hospital ou realizam atendimento a domicílio (Tabela 3). 
Tabela 3 - Porcentagem de participantes que trabalham em determinado contexto e que consideram importante analisar determinada informação durante o tratamento de feridas por fonte de informação utilizada, em relação a todos os participantes daquele subgrupo.

\begin{tabular}{|c|c|c|c|c|c|c|c|c|c|}
\hline & \multicolumn{3}{|c|}{ posto de saúde } & \multicolumn{3}{|c|}{ hospital } & \multicolumn{3}{|c|}{ atendimento em domicílio } \\
\hline & 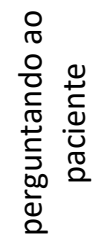 & 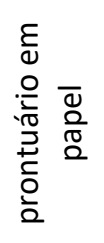 & 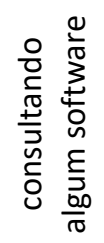 & 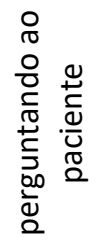 & 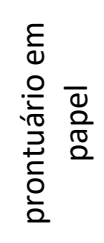 & 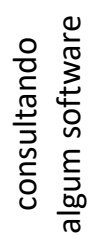 & 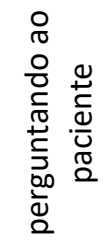 & 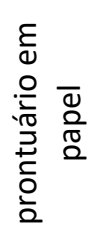 & 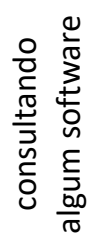 \\
\hline $\begin{array}{l}\text { histórico de } \\
\text { saúde }\end{array}$ & $73 \%$ & $36 \%$ & $0 \%$ & $100 \%$ & $67 \%$ & $11 \%$ & $83 \%$ & $67 \%$ & $17 \%$ \\
\hline & $82 \%$ & $64 \%$ & $0 \%$ & $89 \%$ & $78 \%$ & $11 \%$ & $100 \%$ & $83 \%$ & $17 \%$ \\
\hline $\begin{array}{c}\text { exames } \\
\text { laboratoriais }\end{array}$ & $27 \%$ & $55 \%$ & $0 \%$ & $0 \%$ & $100 \%$ & $11 \%$ & $50 \%$ & $83 \%$ & $17 \%$ \\
\hline medicamentos & $82 \%$ & $45 \%$ & $0 \%$ & $89 \%$ & $100 \%$ & $11 \%$ & $83 \%$ & $33 \%$ & $0 \%$ \\
\hline alergias & $82 \%$ & $18 \%$ & $0 \%$ & $78 \%$ & $44 \%$ & $11 \%$ & $100 \%$ & $33 \%$ & $17 \%$ \\
\hline $\begin{array}{l}\text { doenças } \\
\text { crônicas }\end{array}$ & $91 \%$ & $55 \%$ & $0 \%$ & $89 \%$ & $56 \%$ & $11 \%$ & $100 \%$ & $67 \%$ & $17 \%$ \\
\hline
\end{tabular}

Em ambiente hospitalar, no entanto, o paciente se equilibra com o prontuário em papel como fontes de informação mais utilizadas pelos participantes. A única exceção em todos os casos são os exames laboratoriais obtidos principalmente em prontuários em papel. Uma pequena porcentagem de participantes que usam software como fonte de informação no tratamento de feridas apareceu apenas em hospitais e atendimentos em domicílios, sem nenhuma referência em postos de saúde (Tabela 3). Para aqueles que trabalham em posto de saúde, o paciente se destacou como fontes de informação sobre doenças crônicas (91\% dos participantes) e sobre tratamentos anteriores de ferida, medicamentos consumidos e alergias ( $82 \%$ dos participantes, cada). No ambiente hospitalar, os pacientes se destacaram como fonte de informação sobre seu estado de saúde ( $100 \%$ dos participantes) e os prontuários em papel como fonte de informação sobre medicamentos e resultados de exames ( $100 \%$ dos participantes). Já no atendimento em domicílio, $100 \%$ dos participantes perguntam ao paciente sobre seus tratamentos anteriores de feridas, alergias e doenças crônicas.

Em geral, no ambiente hospitalar e nos postos de saúde, os participantes conseguem obter informações sobre o histórico de saúde, tratamentos anteriores de feridas, resultados de exames laboratoriais, medicamentos consumidos, alergias e 
doenças crônicas do paciente de tratamento de feridas (Tabela 4). Nesses ambientes, as situações em que os participantes conseguem sempre obter as essas informações costumam ser mais frequentes do que as situações em que algumas vezes eles conseguem obtê-las, exceto sobre tratamento anteriores, exames laboratoriais e alergias em postos de saúde onde esta frequência se inverte. Quase nenhum participante afirmou que não consegue obter essas informações. Apenas um deles que trabalha em hospital reportou impossibilidade de acesso a informações sobre tratamentos anteriores de ferida. Em atendimento em domicílio, os participantes indicaram que conseguem obter algumas vezes com mais frequência do que sempre as informações sobre histórico de saúde do paciente e sobre tratamento anteriores de ferida. Eles não reportaram nada sobre as demais informações, nem indicaram não conseguir obtê-las. Aqui, os destaques foram $82 \%$ dos participantes que trabalham em posto de saúde obtém sempre que necessário informações sobre medicamentos consumidos e doenças crônicas, e 89\% dos participantes que trabalham em hospital sempre conseguem obter informações sobre doenças crônicas.

Tabela 4 - Porcentagem de participantes que trabalham em um contexto e que consideram importante analisar determinada informação durante o tratamento de feridas por frequência de obtenção da informação, em relação a todos os participantes daquele subgrupo.

\begin{tabular}{|c|c|c|c|c|c|c|c|c|c|}
\hline & \multicolumn{3}{|c|}{ posto de saúde } & \multicolumn{3}{|c|}{ hospital } & \multicolumn{3}{|c|}{ atendimento em domicílio } \\
\hline & 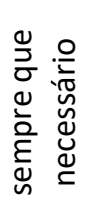 & 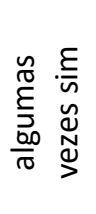 & 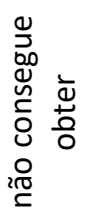 & 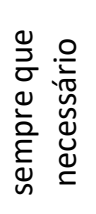 & 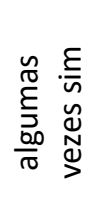 & 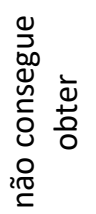 & 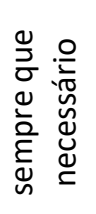 & 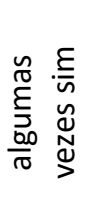 & 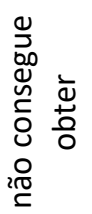 \\
\hline $\begin{array}{l}\text { histórico de } \\
\text { saúde }\end{array}$ & $36 \%$ & $45 \%$ & $0 \%$ & $56 \%$ & $44 \%$ & $0 \%$ & $33 \%$ & $67 \%$ & $0 \%$ \\
\hline $\begin{array}{l}\text { tratamentos } \\
\text { anteriores }\end{array}$ & $18 \%$ & $64 \%$ & $0 \%$ & $44 \%$ & $44 \%$ & $11 \%$ & $33 \%$ & $67 \%$ & $0 \%$ \\
\hline $\begin{array}{c}\text { exames } \\
\text { laboratoriais }\end{array}$ & $27 \%$ & $45 \%$ & $0 \%$ & $44 \%$ & $56 \%$ & $0 \%$ & $0 \%$ & $0 \%$ & $0 \%$ \\
\hline medicamentos & $82 \%$ & $9 \%$ & $0 \%$ & $67 \%$ & $33 \%$ & $0 \%$ & $0 \%$ & $0 \%$ & $0 \%$ \\
\hline alergias & $36 \%$ & $45 \%$ & $0 \%$ & $67 \%$ & $22 \%$ & $0 \%$ & $0 \%$ & $0 \%$ & $0 \%$ \\
\hline $\begin{array}{l}\text { doenças } \\
\text { crônicas }\end{array}$ & $82 \%$ & $27 \%$ & $0 \%$ & $89 \%$ & $11 \%$ & $0 \%$ & $0 \%$ & $0 \%$ & $0 \%$ \\
\hline
\end{tabular}


O registro de informações sobre o tratamento de feridas variou conforme o local de trabalho (Tabela 5). Proporcionalmente, $83 \%$ dos profissionais que atendem em domicílio, $82 \%$ dos que trabalham em posto de saúde e $67 \%$ dos que trabalham em hospital fazem anotações em papel sobre o tratamento de feridas. A grande maioria (89\%) dos profissionais que trabalham em hospital tiram fotos, seguidos por $73 \%$ dos que trabalham em posto de saúde e $67 \%$ dos que atendem em domicílio. Existe uma diferença significativa entre os $50 \%$ e $44 \%$ dos profissionais que fazem registro de informações em computador, respectivamente, em hospitais e sobre atendimentos em domicílio, comparado com apenas $9 \%$ de profissionais que de profissionais que realizam atendimentos em postos de saúde.

Tabela 5 - Porcentagem de participantes que trabalham em um contexto por modo de registro de informações sobre tratamento de feridas, em relação a todos que trabalham naquele contexto.

\begin{tabular}{|c|c|c|c|c|c|}
\hline & anota em papel & anota em celular & anota computador & tira foto & grava áudio \\
\hline $\begin{array}{l}\text { sem resposta } \\
\text { ou experiência }\end{array}$ & $83 \%$ & $11 \%$ & $17 \%$ & $50 \%$ & $6 \%$ \\
\hline Outros & $33 \%$ & $11 \%$ & $11 \%$ & $33 \%$ & $0 \%$ \\
\hline posto de saúde & $82 \%$ & $0 \%$ & $9 \%$ & $73 \%$ & $0 \%$ \\
\hline Hospital & $67 \%$ & $11 \%$ & $44 \%$ & $89 \%$ & $0 \%$ \\
\hline $\begin{array}{l}\text { atendimento } \\
\text { em domicílio }\end{array}$ & $83 \%$ & $17 \%$ & $50 \%$ & $67 \%$ & $0 \%$ \\
\hline
\end{tabular}

O uso de dispositivos de informática foi similar entre as faixas etárias dos participantes (Tabela 6). Houve uma variação de $8 \%$ entre as faixas etárias no uso do computador. A variação no uso do celular entre as faixas etárias foi de $16 \%$. As faixas etárias de 18-24 anos e de 30-39 anos se destacaram no uso do celular, enquanto que a faixa-etária de 40-49 anos apresentou uma porcentagem menor que as demais. O tablet teve uma porcentagem de uso pequena, com destaque na faixa etária de 30-39 anos. A idade não pareceu influenciar significativamente o uso desses dispositivos tecnológicos. Em geral, o uso do celular foi ligeiramente maior do que o computador, enquanto o uso do tablet foi bem menor. 
Tabela 6 - Porcentagem de participantes em uma faixa etária que usa um tipo de dispositivos de informática, em relação a todos os participantes daquela faixa etária.

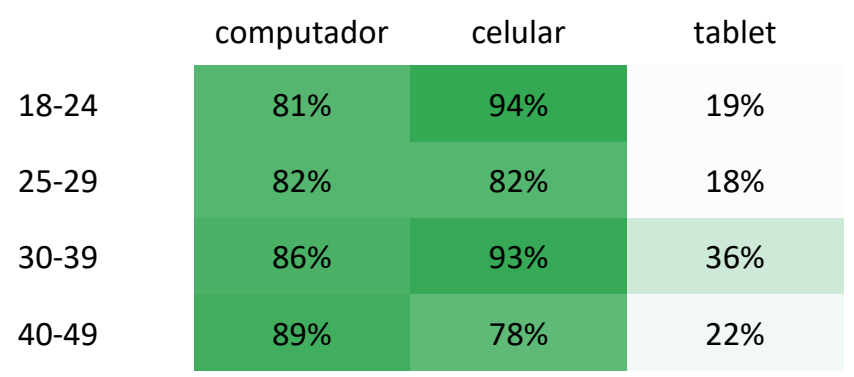

Fonte: Participantes da pesquisa.

O uso que cada faixa etária faz dos tipos de software investigados variou significativamente (Tabela 7). A faixa etária de 30-39 anos se destacou, seguida pela faixa dos 25-29 anos, depois pela faixa dos 18-24 anos e, por último, pela faixa etária de 40-49 anos. Apesar de algumas poucas exceções na faixa etárias de 18-24 anos e de 40-49 anos, a tendência de frequência de uso dos tipos de softwares seguiu em ordem decrescente em todas as faixas etárias: redes sociais, e-mail, softwares de escritório (editor de texto, planilha, etc.), sites de notícias e jogos. Considerando a diversidade de dispositivos e softwares utilizados pelos participantes é possível afirmar que eles estão familiarizados com a informática em atividades pessoais. Portanto aversão, resistência e grande dificuldade no uso da informática não justificam sua não adoção nas atividades profissionais destes participantes.

Tabela 7 - Porcentagem de participantes por faixa etária que usa um tipo de software, em relação a todos os participantes daquela faixa etária.

\begin{tabular}{|c|c|c|c|c|c|}
\hline & redes sociais & e-mail & escritório & notícias & jogos \\
\hline $18-24$ & $56 \%$ & $44 \%$ & $56 \%$ & $31 \%$ & $13 \%$ \\
\hline $25-29$ & $82 \%$ & $73 \%$ & $64 \%$ & $64 \%$ & $36 \%$ \\
\hline $30-39$ & $100 \%$ & $93 \%$ & $79 \%$ & $79 \%$ & $36 \%$ \\
\hline $40-49$ & $78 \%$ & $67 \%$ & $44 \%$ & $78 \%$ & $11 \%$ \\
\hline
\end{tabular}

Fonte: Participantes da pesquisa.

O modo de registrar informações sobre o tratamento de feridas apresentou pontos de variação mais significativa entre as faixas etárias (Tabela 8). A faixa etária de 18-24 anos se destacou em quase todas as formas de registro com uma vantagem de até $30 \%$, exceto na porcentagem daqueles que anotam no computador que foi maior na faixa 
de 25-29 anos. Nas demais faixas etárias e demais modos de registro, as diferenças foram de até $11 \%$. Assim, após 25 anos, geralmente quando se inicia ou intensifica a atuação profissional com a conclusão da educação superior, a idade isoladamente foi um fator pouco significativo no comportamento dos participantes durante o registro de informações sobre o tratamento de feridas.

Tabela 8 - Porcentagem de participantes por faixa etária que registram de um modo as informações produzidas durante o tratamento de feridas, em relação a todos os participantes daquela faixa etária.

\begin{tabular}{cccccc} 
& anota em papel & anota em celular & anota computador & tira foto & grava áudio \\
\hline $18-24$ & $94 \%$ & $13 \%$ & $25 \%$ & $81 \%$ & $6 \%$ \\
\hline $25-29$ & $64 \%$ & $9 \%$ & $36 \%$ & $55 \%$ & $0 \%$ \\
$30-39$ & $57 \%$ & $7 \%$ & $14 \%$ & $50 \%$ & $0 \%$ \\
$40-49$ & $67 \%$ & $11 \%$ & $11 \%$ & $44 \%$ & $0 \%$
\end{tabular}

A atuação profissional dos participantes influenciou a importância que atribuíam às informações sobre a saúde do paciente durante o tratamento de feridas (Tabela 9). Mais enfermeiros consideraram as informações indicadas no questionário como importantes, seguidas pelos estudantes de graduação em enfermagem, e depois pelos técnicos de enfermagem. A única exceção a esta ordem foi a porcentagem maior de técnicos de enfermagem que indicaram doenças crônicas como importante comparada a porcentagem de estudantes de graduação em enfermagem.

Tabela 9 - Porcentagem de participantes de uma atuação profissional que consideram importante analisar uma informação sobre o paciente durante o tratamento de feridas, em relação a todos com a mesma atuação profissional.

\begin{tabular}{cccccccc}
\hline & $\begin{array}{c}\text { histórico } \\
\text { de saúde }\end{array}$ & $\begin{array}{c}\text { doenças } \\
\text { crônicas }\end{array}$ & $\begin{array}{c}\text { tratamentos } \\
\text { de feridas }\end{array}$ & alergias & exames & $\begin{array}{c}\text { medicamentos } \\
\text { consumidos }\end{array}$ \\
\hline enfermeiro & $100 \%$ & $88 \%$ & $81 \%$ & $75 \%$ & $81 \%$ & $75 \%$ \\
\hline estudante & $80 \%$ & $73 \%$ & $67 \%$ & $53 \%$ & $47 \%$ & $53 \%$ \\
\hline técnico em enfermagem & $64 \%$ & $82 \%$ & $64 \%$ & $45 \%$ & $27 \%$ & $45 \%$
\end{tabular}

Fonte: Participantes da pesquisa.

Comportamento semelhante ocorreu quando os participantes de cada atuação 
profissional indicaram as informações importantes sobre as feridas (Tabela 10). Os enfermeiros apontaram como importantes as características indicadas no questionário em porcentagem maior do que os estudantes de graduação em enfermagem, que por sua vez foram maiores do que os indicados pelos técnicos de enfermagem. A única exceção nesta ordem ocorreu com o tamanho das partes internas da ferida em que os estudantes indicaram porcentagem maior do que os enfermeiros. Vale notar que quase todos os enfermeiros indicam aparência e textura dos tecidos que compõem a ferida e sua profundidade como importantes de serem analisadas durante o tratamento de feridas.

Tabela 10 - Porcentagem de participantes de uma atuação profissional que consideram importante analisar uma informação sobre as feridas durante o tratamento, em relação a todos com a mesma atuação profissional.

\begin{tabular}{ccccc} 
& $\begin{array}{c}\text { tamanho do } \\
\text { contorno }\end{array}$ & $\begin{array}{c}\text { tamanho das } \\
\text { partes }\end{array}$ & $\begin{array}{c}\text { aparência e } \\
\text { textura }\end{array}$ & profundidade \\
\hline Enfermeiro & $81 \%$ & $69 \%$ & $94 \%$ & $100 \%$ \\
\hline Estudante & $67 \%$ & $80 \%$ & $80 \%$ & $87 \%$ \\
\hline técnico em enfermagem & $64 \%$ & $55 \%$ & $55 \%$ & $73 \%$ \\
\hline
\end{tabular}

Fonte: Participantes da pesquisa.

A atuação profissional dos participantes influenciou o modo como registram as informações sobre o tratamento de feridas (Tabela 11). A porcentagem de enfermeiros que anotam em papel é um pouco maior (+2 participantes, $+8 \%)$ da indicada pelos estudantes de graduação em enfermagem, que por sua vez é bem maior (+6 participantes, $+25 \%)$ da indicada pelos técnicos de enfermagem. Já a porcentagem de enfermeiros que tiram fotos das feridas é bem maior ( +7 participantes, $+41 \%$ ) do que as apresentadas pelos estudantes de graduação, que por sua vez foi um pouco maior $(+3$ participantes, $+11 \%$ ) do que os técnicos de enfermagem. Nos demais modos de registro indicados no questionário, os enfermeiros também se destacaram em relação aos demais. 
Tabela 11 - Porcentagem de participantes de uma atuação profissional que registram informações sobre o tratamento de feridas de determinado modo, em relação a todos com a mesma atuação.

\begin{tabular}{cccccc} 
& anota em papel & anota em celular & anota computador & tira foto & grava áudio \\
\hline enfermeiro & $88 \%$ & $19 \%$ & $38 \%$ & $88 \%$ & $6 \%$ \\
$\begin{array}{c}\text { estudante } \\
\text { técnico em } \\
\text { enfermagem }\end{array}$ & $80 \%$ & $7 \%$ & $13 \%$ & $47 \%$ & $0 \%$ \\
\hline
\end{tabular}

Fonte: Participantes da pesquisa.

O tempo de experiência profissional influenciou a frequência em que os participantes indicaram como importantes as informações sobre a saúde do paciente durante o tratamento de feridas (Tabela 12). Contudo, não foi possível perceber uma tendência. Algumas vezes a porcentagem de participantes com menor tempo de experiência foi menor do que a apresentada por aqueles que possuem maior experiência, em outras comparações ocorreu o oposto. Os participantes que possuem de dois a cinco anos de experiência apresentaram porcentagens maiores em geral, seguidos por aqueles que possuem menos de seis meses de experiência. O histórico de saúde foi considerado importante por todos os participantes com de dois a cinco anos de experiência. Já as doenças crônicas foram consideradas importantes por todos os participantes com menos de seis meses e por aqueles com mais de cinco anos com experiência.

Tabela 12 - Porcentagem de participantes com determinado período de tempo de experiência profissional que consideram importante consultar determinada informação sobre o paciente durante o tratamento de feridas, em relação a todos os participantes com o mesmo período de experiência.

\begin{tabular}{ccccccc} 
& $\begin{array}{c}\text { histórico } \\
\text { de saúde }\end{array}$ & $\begin{array}{c}\text { doenças } \\
\text { crônicas }\end{array}$ & $\begin{array}{c}\text { tratamentos } \\
\text { anteriores }\end{array}$ & alergias & exames & $\begin{array}{c}\text { medicamentos } \\
\text { consumidos }\end{array}$ \\
\hline não trata feridas & $78 \%$ & $70 \%$ & $63 \%$ & $56 \%$ & $48 \%$ & $52 \%$ \\
\hline$<6$ meses & $83 \%$ & $100 \%$ & $83 \%$ & $67 \%$ & $83 \%$ & $83 \%$ \\
\hline 6 meses - 2 anos & $71 \%$ & $86 \%$ & $71 \%$ & $29 \%$ & $29 \%$ & $29 \%$ \\
$2-5$ anos & $100 \%$ & $83 \%$ & $83 \%$ & $83 \%$ & $83 \%$ & $83 \%$ \\
$>5$ anos & $75 \%$ & $100 \%$ & $50 \%$ & $75 \%$ & $50 \%$ & $75 \%$
\end{tabular}

Fonte: Participantes da pesquisa.

Algo semelhante aconteceu com as informações sobre feridas (Tabela 13). 0 
tempo de experiência profissional influenciou a porcentagem de participantes que consideraram importante consultar informações sobre as feridas. Aqui também não foi possível identificar uma tendência. Novamente, as maiores porcentagens ocorreram naqueles participantes com menos de seis meses de experiência e naqueles com de dois até cinco anos de experiência. $O$ tamanho das partes internas das feridas foi considerado importante por todos os participantes entre dois e cinco anos de experiência. A profundidade da ferida foi considerada importante por todos os participantes a partir de dois anos de experiência.

Tabela 13 - Porcentagem de participantes com determinado período de tempo de experiência profissional que consideram importante consultar determinada informação sobre as feridas durante o tratamento, em relação a todos os participantes com o mesmo período de experiência.

\begin{tabular}{ccccc}
\hline & tamanho do contorno & tamanho das partes & aparência & profundidade \\
\hline $\begin{array}{c}\text { não trata feridas } \\
\text { <6 meses }\end{array}$ & $74 \%$ & $63 \%$ & $74 \%$ & $85 \%$ \\
\hline 6 meses - 2 anos & $67 \%$ & $83 \%$ & $83 \%$ & $83 \%$ \\
\hline $2-5$ anos & $57 \%$ & $43 \%$ & $71 \%$ & $71 \%$ \\
\hline$>5$ anos & $83 \%$ & $100 \%$ & $83 \%$ & $100 \%$ \\
\hline
\end{tabular}

Fonte: Participantes da pesquisa.

Não ter costume de utilizar o celular não dificultou que os participantes tirem fotos de feridas. Todos os seis participantes que afirmaram não usar celular habitualmente já registraram as feridas em fotos. Eles provavelmente utilizaram outros dispositivos para isso, como uma câmera fotográfica, ou utilizaram celulares emprestados de colegas de trabalho. Apenas $66 \%$ dos participantes que possuem celular tiraram fotos das feridas. Aproximadamente $61 \%$ das pessoas que consideram importante analisar as características visuais das feridas tiraram fotos das feridas, contra quase $39 \%$ dos que não tiraram fotos. Deste modo, considerar uma característica visual importante aumentou em $58 \%$ as chances de tirar fotos da ferida. 


\section{CONCLUSÃO}

Este trabalho investigou necessidades informacionais de profissionais de enfermagem durante o tratamento de feridas através da aplicação de um questionário com 14 perguntas. Os 50 participantes eram principalmente enfermeiros, estudantes de graduação em enfermagem e técnicos em enfermagem. Alguns desses, no entanto, eram profissionais de outras áreas interessados no tratamento de feridas. A faixa etária dos participantes foi bem distribuída entre 18 e 49 anos. Suas atuações profissionais no tratamento de feridas ocorriam em postos de saúde, hospitais e atendimento em domicílio. O tempo de experiência teve distribuição equilibrada, com concentração média de atendimentos diários pequena, perto de 2 e 5 pacientes. A maioria dos participantes relatou familiaridade com informática, usando principalmente computador e celular com uma diversidade de softwares.

Foram identificadas informações relevantes sobre o paciente e suas feridas que devem ser analisadas durante os atendimentos para tratamento de feridas. Essas informações geralmente são obtidas perguntando ao paciente e em prontuários em papel, muito raramente um software é utilizado como fonte destas informações. Os registros de informações produzidas são realizados principalmente anotando em papel e tirando fotos, mas também anota-se em computador e celular e até grava-se áudio. Foram identificados 7 apoios informacionais que um software pode oferecer aos profissionais de enfermagem durante o tratamento de feridas: facilitar o diálogo entre profissionais; aumentar a eficiência no atendimento; facilitar o trabalho dos profissionais de enfermagem; apoiar o diagnóstico das feridas; melhorar a precisão e eficácia do tratamento de feridas; receber orientações sobre como realizar o tratamento de feridas; e apoio para visualizar e analisar o histórico do tratamento de feridas.

Alguns comportamentos informacionais foram influenciados pelos perfis dos participantes, em particular pelo local de trabalho e pelo tipo de atuação profissional (enfermeiro, estudante de graduação em enfermagem e técnico). A idade não foi determinante para os modos de registro de informação, nem para o uso de informática.

Trabalhos futuros devem ampliar a amostragem deste estudo e aplicar o que foi aprendido no atendimento às necessidades informacionais, em particular quando 
mediado pela informática.

\section{REFERÊNCIAS}

CRESWELL, J.W. Projeto de pesquisa: Método Qualitativo, Quantitativo e Misto. 3. ed. Artmed, 2010.

FIGUEIREDO, N.M. Estudo de uso e usuários da informação. Brasília: Ibict, 1994.

FINK, A. The Survey Handbook. 2nd ed. London, UK; Thousand Oaks, CA: Sage Publications, 2003.

GARCIA, T.R.; NOBREGA, M.M.L. Processo de enfermagem: da teoria à prática assistencial e de pesquisa. Esc. Anna Nery Rev Enferm., v. 13, n. 1, p. 816-818, jan./mar. 2009.

KORDESTANI, S.S. Wound Care Management. In: KORDESTANI, S.S. (ed.) Atlas of Wound Healing: A Tissue Regeneration Approach. St. Louis, MO: Elsevier, 2019. Chapter 5, p. 3147.

MARTINEZ-SILVEIRA, M.; ODDONE, N. Necessidades e comportamento informacional: conceituação e modelos. Ciência da Informação, Brasília, v. 36, n. 2, p. 118-127, ago. 2007.

SANTOS, J.B.D.; PORTO, S.G.; SUZUKI, L.M.; SOSTIZZO, L.Z.; ANTONIAZZI, J.L.; ECHER, I.C. Avaliação e tratamento de feridas: orientações aos profissionais de saúde. Porto Alegre, RS: Hospital de Clínicas de Porto Alegre, 2011. Disponível em: http://hdl.handle.net/10183/34755. Acesso em: 4 dez. 2020.

\section{Declaração de Contribuição dos Autores}

Paulo Vanzolini Moura da Silva - Investigação - Metodologia - Análise Formal Visualização - Escrita (rascunho original).

Bruno Santana da Silva - Conceptualização - Investigação - Metodologia - Análise Formal - Visualização - Escrita (rascunho original) - Escrita (análise e edição). 